OPEN ACCESS

Edited by:

Xiaoying Gong,

Fujian Normal University, China

Reviewed by:

Xiao-Tao Lu,

Institute of Applied Ecology (CAS),

China

Rubén Retuerto,

University of Santiago

de Compostela, Spain

*Correspondence:

Zhenqing $\mathrm{Li}$

lizq@ibcas.ac.cn

Specialty section:

This article was submitted to

Functional Plant Ecology,

a section of the journal

Frontiers in Plant Science

Received: 11 January 2021 Accepted: 19 March 2021

Published: 13 April 2021

Citation:

Liu Y, Xu M, Li G, Wang M, Li Z and De Boeck HJ (2021) Changes

of Aboveground and Belowground

Biomass Allocation in Four Dominant

Grassland Species Across

a Precipitation Gradient.

Front. Plant Sci. 12:650802.

doi: 10.3389/fpls.2021.650802

\section{Changes of Aboveground and Belowground Biomass Allocation in Four Dominant Grassland Species Across a Precipitation Gradient}

\author{
Yongjie Liu' ${ }^{1}$, Mingjie $X u^{1}$, Guoe $L^{1}{ }^{1}$, Mingxia Wang ${ }^{1}$, Zhenqing $L^{2,3 *}$ and \\ Hans J. De Boeck ${ }^{4}$ \\ 'State Key Laboratory of Grassland Agro-Ecosystems, Key Laboratory of Grassland Livestock Industry Innovation, Ministry \\ of Agriculture and Rural Affairs, College of Pastoral Agriculture Science and Technology, Lanzhou University, Lanzhou, China, \\ ${ }^{2}$ State Key Laboratory of Vegetation and Environmental Change, Institute of Botany, Chinese Academy of Sciences, Beijing, \\ China, ${ }^{3}$ University of Chinese Academy of Sciences, Beijing, China, ${ }^{4}$ Plants and Ecosystems (PLECO), Department \\ of Biology, University of Antwerp, Wilrijk, Belgium
}

Climate change is predicted to affect plant growth, but also the allocation of biomass to aboveground and belowground plant parts. To date, studies have mostly focused on aboveground biomass, while belowground biomass and allocation patterns have received less attention. We investigated changes in biomass allocation along a controlled gradient of precipitation in an experiment with four plant species (Leymus chinensis, Stipa grandis, Artemisia frigida, and Potentilla acaulis) dominant in Inner Mongolia steppe. Results showed that aboveground biomass, belowground biomass and total biomass all increased with increasing growing season precipitation, as expected in this water-limited ecosystem. Biomass allocation patterns also changed along the precipitation gradient, but significant variation between species was apparent. Specifically, the belowground biomass: aboveground biomass ratio (i.e., B:A ratio) of S. grandis was not impacted by precipitation amount, while B:A ratios of the other three species changed in different ways along the gradient. Some of these differences in allocation strategies may be related to morphological differences, specifically, the presence of rhizomes or stolons, though no consistent patterns emerged. Isometric partitioning, i.e., constant allocation of biomass aboveground and belowground, seemed to occur for one species ( $S$. grandis), but not for the three rhizome or stolonforming ones. Indeed, for these species, the slope of the allometric regression between log-transformed belowground biomass and log-transformed aboveground biomass significantly differed from 1.0 and B:A ratios changed along the precipitation gradient. As changes in biomass allocation can affect ecosystem functioning and services, our results can be used as a basis for further studies into allocation patterns, especially in a context of environmental change.

Keywords: aboveground biomass, belowground biomass, climate change, grassland, grassland persistence, rangeland sustainability, precipitation amount 


\section{INTRODUCTION}

Climate change is affecting rainfall patterns in many regions around the world (Arnbjerg-Nielsen et al., 2013; Ohba and Sugimoto, 2019; Hyun and Yeh, 2020). Such changes can significantly alter plant growth and vegetation dynamics, both when precipitation amounts decrease or when they increase (Felton et al., 2019). Drought triggers mostly neutral or negative responses regarding growth and biomass (Zhang et al., 2012; Gherardi and Sala, 2019; Meng et al., 2019), while increased precipitation mostly leads to neutral or positive growth responses (Chu et al., 2016; Michaletz et al., 2018; Gherardi and Sala, 2019). While these are general patterns, where the biomass ends up under any response scenario (decreased, increased, or unchanged biomass) is also relevant as this can affect, for example, livestock feeding, soil stability, and carbon sequestration (Herrero et al., 2013; Maryol and Lin, 2015; Reinhart and Vermeire, 2017).

The optimal partitioning theory predicts that plants tend to allocate relatively more biomass to organs increasing the uptake of the most limiting resources (Bloom et al., 1985; Gedroc et al., 1996; Mao et al., 2012). Therefore, plants are expected to allocate more biomass belowground under dry conditions, and more aboveground when growing under wet conditions (Villar et al., 1998). The isometric partitioning theory suggests that aboveground biomass and belowground biomass follows an isometric pattern (Enquist and Niklas, 2002; Wang et al., 2014), implying that there is not necessarily a trade-off between aboveground and belowground. However, contrasting results have been found, with both studies in support (e.g., Enquist and Niklas, 2002; Wang et al., 2014) and studies that rejected isometric partitioning (e.g., Chen et al., 2016; Ma and Wang, 2021). Thus, further studies are needed to shed more light on this theory.

While it is clear that environmental changes can significantly affect biomass allocation (Fan et al., 2009; Zhang et al., 2017; Yang et al., 2018; Zhou et al., 2020), most studies that explored the effects of climate change on biomass allocation have focused on aboveground biomass (Bai and Xu, 1997; Mokany et al., 2006; Bai et al., 2008; Gonzalez-Dugo et al., 2010). Few studies include belowground biomass as this is more difficult to measure, especially in the field (Milchunas et al., 2005; Ma et al., 2008). Therefore, our knowledge of changes in plant allocation pattern triggered by changes in the environment is generally incomplete (Achten et al., 2010; Liu et al., 2015) and exact allocation strategies merit further investigation (Pan et al., 2005; Cai et al., 2005; Lv et al., 2016).

Grasslands, as one of the main terrestrial ecosystems, occupy more than $30 \%$ of the terrestrial area (Parton et al., 2012). They play an important role in biogeochemical cycles and energy transformation (Huang et al., 2010; Bai et al., 2012). Compared with forests, grasslands show more pronounced responses to climate change, at least in the short term (Eziz et al., 2017; Maurer et al., 2020), and are thus a relevant ecosystem to study in the context of environmental change. In grasslands, biomass allocation is a key mechanism for understanding the dynamics involved in plant growth, and changes therein can alter the structure and functioning of these systems (Poorter et al., 2012a,b).
To improve the knowledge on changes in biomass allocation patterns under varying environmental conditions in grasslands, we conducted an experiment to explore effects of growing season precipitation on biomass aboveground and belowground. We focused on four plant species (i.e., Leymus chinensis, Stipa grandis, Artemisia frigida, and Potentilla acaulis) dominant in Inner Mongolia steppe, and applied a gradient including eight levels of precipitation centered around the local annual mean precipitation. L. chinensis is a perennial forage grass with long strong rhizomes, $S$. grandis is a perennial tussock grass with closely clumped shoots, while $A$. frigida and $P$. acaulis are perennial herbs with stolons and developed adventitious roots (Li et al., 2005; Liu et al., 2006, 2007). The objective of this study was to test the optimal partitioning theory and the isometric partitioning theory at the species scale. Specially, we aimed to explore the relationships between precipitation amount and aboveground biomass, belowground biomass, total biomass and belowground biomass: aboveground biomass (B:A) ratio. Previous studies found that species with rhizomes or stolons tended to allocate more biomass to roots (i.e., belowground) (Schmid, 1987; Enquist and Niklas, 2002; Rhazi et al., 2009), leading to hypothesis (1), namely that the B:A ratio of L. chinensis, A. frigida, and $P$. acaulis is expected to be larger than that of $S$. grandis. Furthermore, if species with rhizomes or stolons indeed allocate more biomass belowground, they may respond differently along a gradient of changing precipitation compared to other species, according to the optimal partitioning theory. Under this hypothesis (2) the B:A ratios of L. chinensis, A. frigida, and $P$. acaulis would increase with precipitation amount, while a different pattern may be apparent in S. grandis. However, under the isometric partitioning hypothesis (3), the B:A ratios of these species are expected to be constant with precipitation amount (Enquist and Niklas, 2002; Yang and Luo, 2011; Wang et al., 2014). This same hypothesis also states that aboveground biomass should be scale with belowground biomass across our dataset.

\section{MATERIALS AND METHODS}

\section{Field Site}

This study was conducted on Inner Mongolia steppe in China $\left(43^{\circ} 33^{\prime} \mathrm{N}, 116^{\circ} 40^{\prime} \mathrm{E}\right)$, where the mean elevation ranges from 1,200 to $1,250 \mathrm{~m}$. Local climate is characterized by a mild humid summer and a dry cold winter, with the mean annual temperature (MAT) ranging from -1.1 to $0.2^{\circ} \mathrm{C}$, and large seasonal differences $\left(-21.4^{\circ} \mathrm{C}\right.$ on average in the coldest month, January, and $18.5^{\circ} \mathrm{C}$ on average in the warmest month, July). Mean annual precipitation (MAP) is $350 \mathrm{~mm}$ (from 1980 to 2000), of which around $280 \mathrm{~mm}$ falls in the growing season.

\section{Experimental Design}

To explore biomass allocation to aboveground and belowground plant parts, a manipulation experiment was conducted from May 2000 to October 2001. Four plant species dominant in the Inner Mongolia steppe were subjected to eight levels of growing season precipitation (administered through watering), centered around the local MAP (i.e., $350 \mathrm{~mm}$ ): 170, 250, 300, 350, 525, 595, 665, and $700 \mathrm{~mm}$. Such a large gradient enabled us to explore the 
effects of precipitation (including both dry and wet conditions) on plant biomass and biomass allocation, and was not intended to mimic the variation of local rainfall expected under climate change (cf. Kayler et al., 2015). Our experiment was conducted in a plot with a rainout shelter in order to block natural rainfall. This shelter was covered by highly transparent plastic foil upward from $2 \mathrm{~m}$ above the ground in order to prevent warming and to allow wind circulation. The impact on temperature, air humidity and light with such a design is limited (Kreyling et al., 2017).

Plants were grown in pots of $50 \mathrm{~cm}$ height and $30 \mathrm{~cm}$ diameter, filled with soil collected from nearby grasslands (mainly dark chestnut soil with a thin humus layer, cf. Li and Li, 2002; Jia et al., 2005). We used soil from the top $50 \mathrm{~cm}$, which was well mixed and from which roots were carefully removed. There were three replications of each treatment for each species. For L. chinensis, seeds were randomly sown in the pots in early May 2000, and four similar-sized individuals were retained after germination. For $S$. grandis, four ramets with similar size were transplanted into each pot in late May 2000 following unsuccessful seed germination in early May. For $A$. frigida and $P$. acaulis, plants were excavated and ramets were separated into similar size. Four of them were transplanted into each pot in early May 2001. All the plants were first grown in an open air area under natural conditions, and rainout shelters were deployed and treatments were applied from 10 June to 10 September 2001. During the experiment,
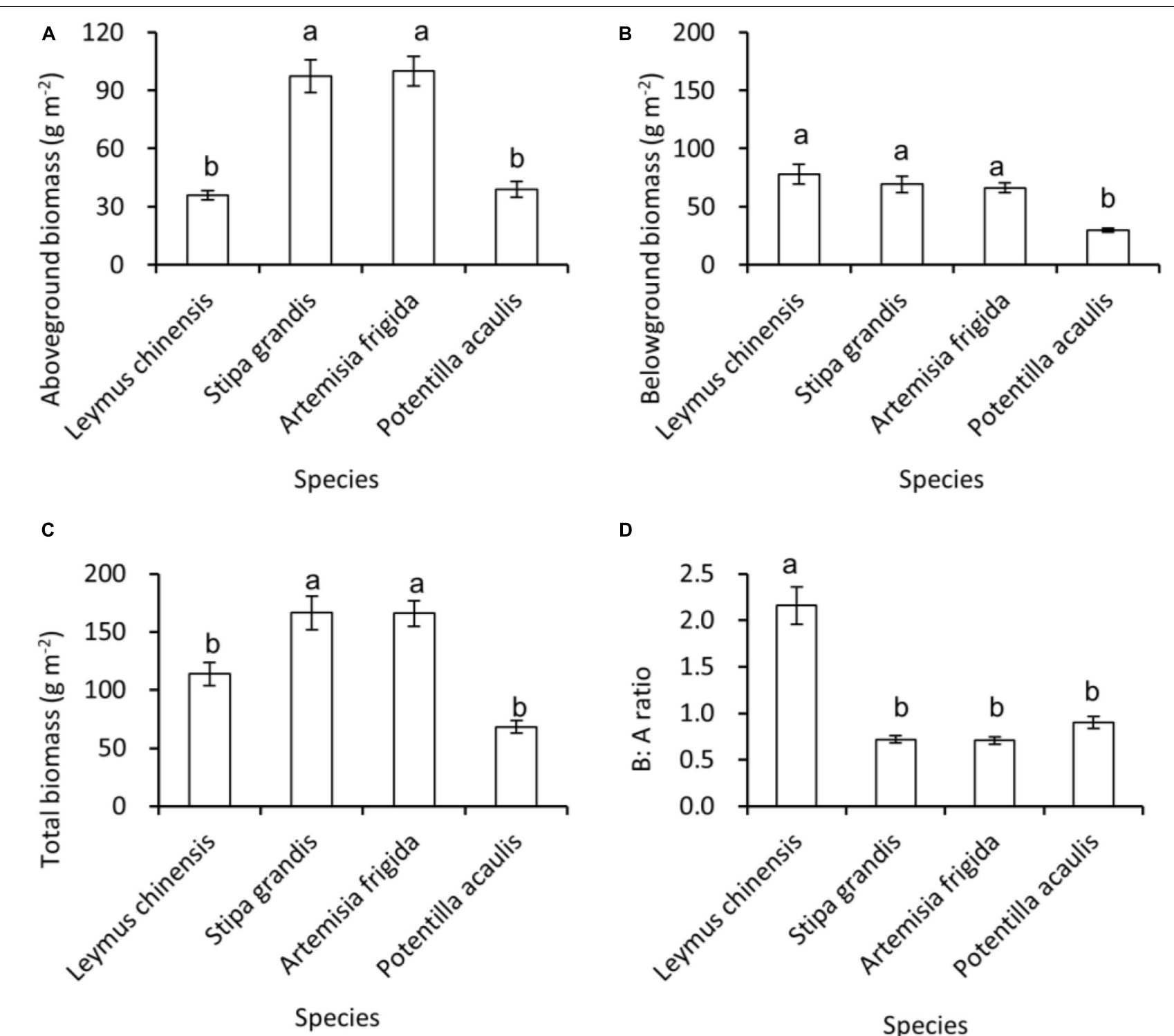

D

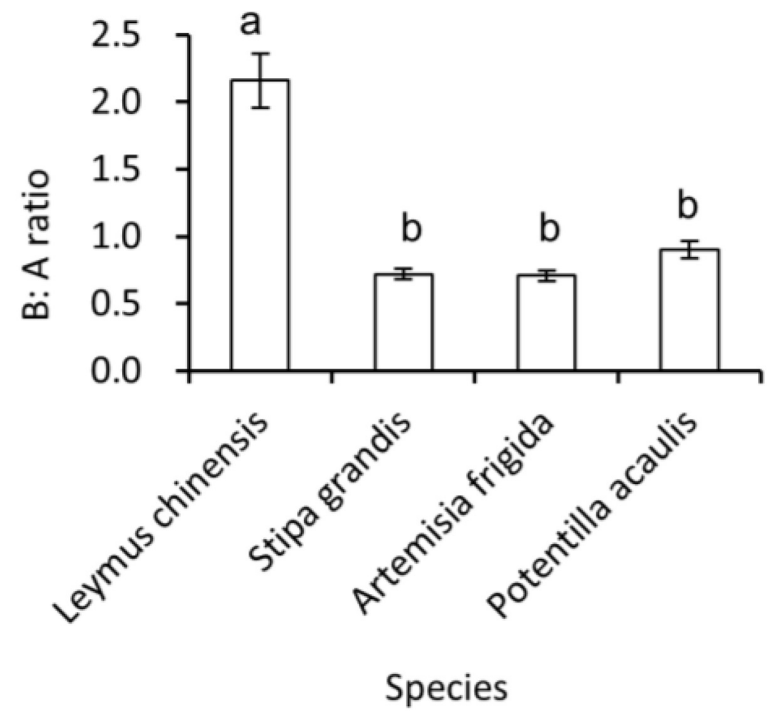

FIGURE 1 | At the pot scale, mean \pm SE of (A) aboveground biomass, (B) belowground biomass, (C) total biomass, and (D) B:A ratio (i.e., ratio of belowground biomass and aboveground biomass), across the precipitation gradient, per species, i.e., Leymus chinensis, Stipa grandis, Artemisia frigida, and Potentilla acaulis. Significant $(P<0.05)$ differences between species have different letters (post hoc analyses with Bonferroni corrections). 
water was added daily to each pot, with the water amount determined by dividing the total amount of precipitation amount in each treatment by the total growing days. To reduce water runoff, water was evenly added by hand at the soil surface. Note that around $80 \%$ of the annual rainfall occurs from June through August. The watering we provided thus covered most of the annual precipitation in line with previous studies (Hagiwara et al., 2010).

At the end of the experiment, all plants were washed free of soil with distilled water, and separated into aboveground and belowground parts. For L. chinensis and S. grandis, aboveground parts included leaves and stems, while belowground parts included roots and rhizomes. For A. frigida, aboveground parts included leaves, flowers, and stems, while belowground parts included roots. Finally, for P. acaulis, aboveground parts included leaves and stems, while belowground parts included roots. All of these were oven-dried at $65^{\circ} \mathrm{C}$ to constant weight and subsequently weighed.

\section{Statistical Analysis}

Aboveground and belowground biomass per square meter was calculated by dividing biomass of the four individuals in each pot by the surface area of each pot. Total biomass relates to the sum of aboveground and belowground biomass and the belowground biomass: aboveground biomass ratio (i.e., B:A ratio) was calculated by dividing belowground biomass by aboveground biomass.

Two-way analysis of variance (ANOVA) was conducted to explore the effects of species, precipitation amount and their interaction on the aboveground biomass, belowground biomass, total biomass and B:A ratio. Post hoc analysis (pairwise comparisons with Bonferroni corrections) was applied to test the differences among the target plant species. One data point of aboveground biomass of $S$. grandis at $700 \mathrm{~mm}$ precipitation was identified as an outlier and was removed. All statistics were carried out using SPSS 21.0.

Curve estimations were done to test the relationships between precipitation amount and aboveground biomass, belowground biomass, total biomass and B:A ratio, where linear, quadratic, power and exponential curves were tested. AIC (Akaike Information Criterion) and $P$ value were used to identify better models, i.e., lower AIC and significant (and lower) $P$ value (Cottingham et al., 2005).

The relationship between log-transformed belowground biomass and log-transformed aboveground biomass across the precipitation gradient was determined with ordinary least square regression and standardized major axis regression (Niklas, 2005; Cheng and Niklas, 2007). The slopes were tested against the 1:1 line, where nonsignificant difference indicates an isometric relationship between belowground and aboveground biomass. Slopes and intercepts were obtained with a software package developed by Falster et al. (2006).

\section{RESULTS}

Regarding species differences, $S$. grandis and A. frigida on average had more aboveground (Figure 1A) and total biomass (Figure 1C) than L. chinensis and P. acaulis. Meanwhile, $P$. acaulis had a lower belowground biomass than the other three plant species (Figure 1B). Interestingly, L. chinensis had a larger B:A ratio than the other species (Figure 1D). Precipitation amount significantly affected aboveground biomass, belowground biomass, total biomass and B:A ratio and these effects differed amount the target plant species (Table 1). Moreover, significant interactive effects of species and precipitation amount on the aboveground biomass, belowground biomass, total biomass and B:A ratio were found (Figures 2-5 and Table 2). Specially, positive patterns were found in relationships between precipitation amount and (i) aboveground biomass (Figure 2), (ii) belowground biomass (Figure 3), and (iii) total biomass (Figure 4).

Along the precipitation gradient, we observed different $\mathrm{B}: \mathrm{A}$ ratios in the four target plant species. Increasing precipitation did not significantly affect the $\mathrm{B}: \mathrm{A}$ ratio of

TABLE 1 | Effects of species, precipitation amount and their interaction in two-way ANOVA on aboveground biomass, belowground biomass, total biomass, and B:A ratio (i.e., ratio of belowground biomass and aboveground biomass).

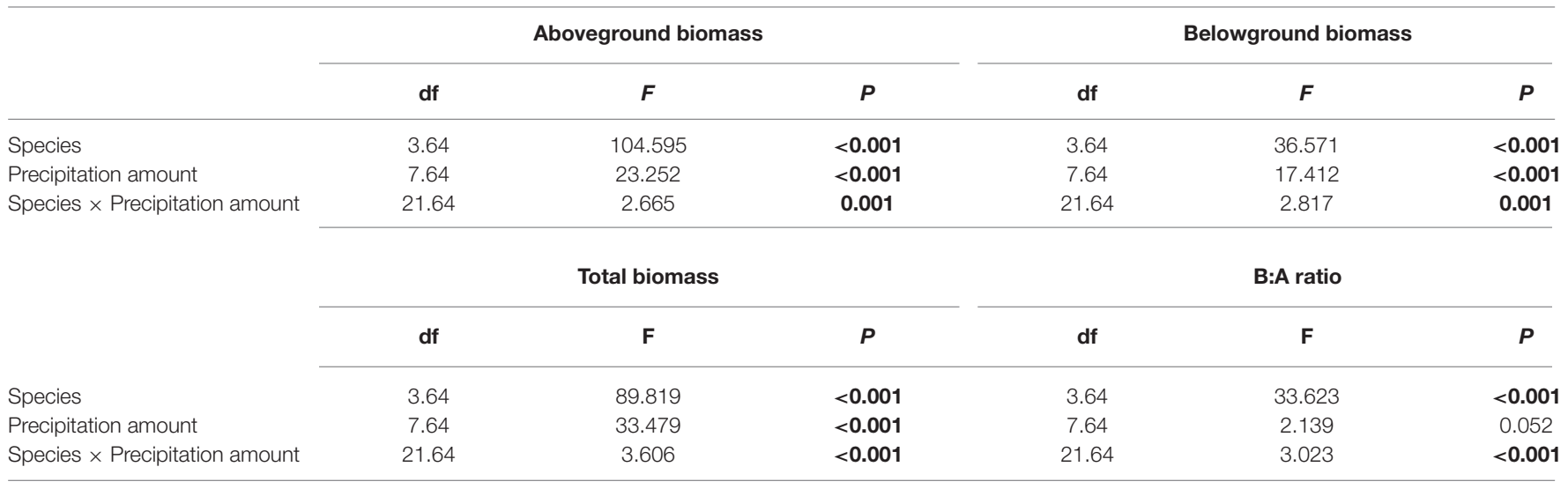

Significant differences are indicated in bold. 


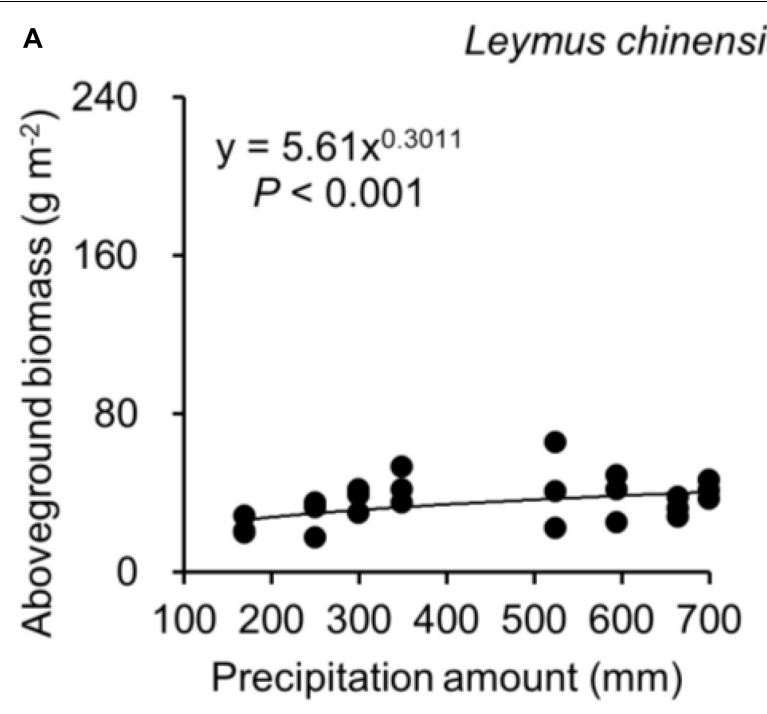

C

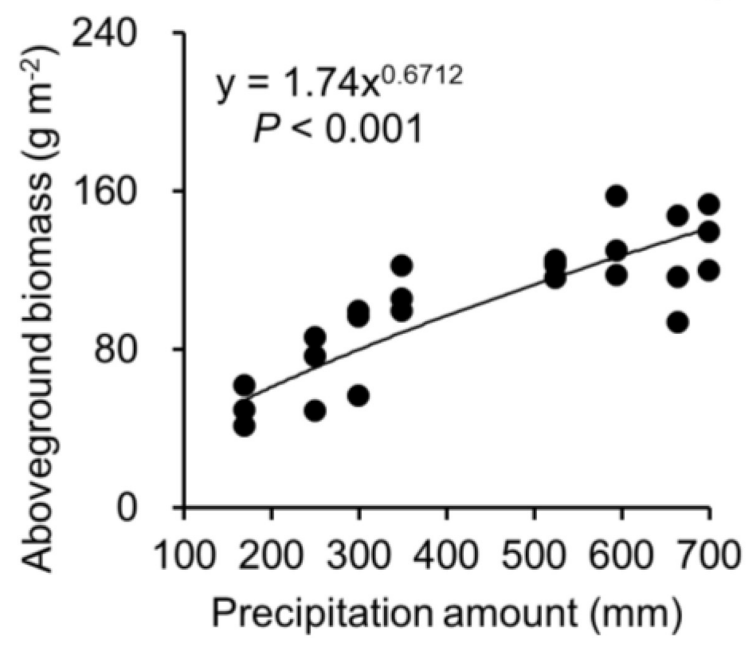

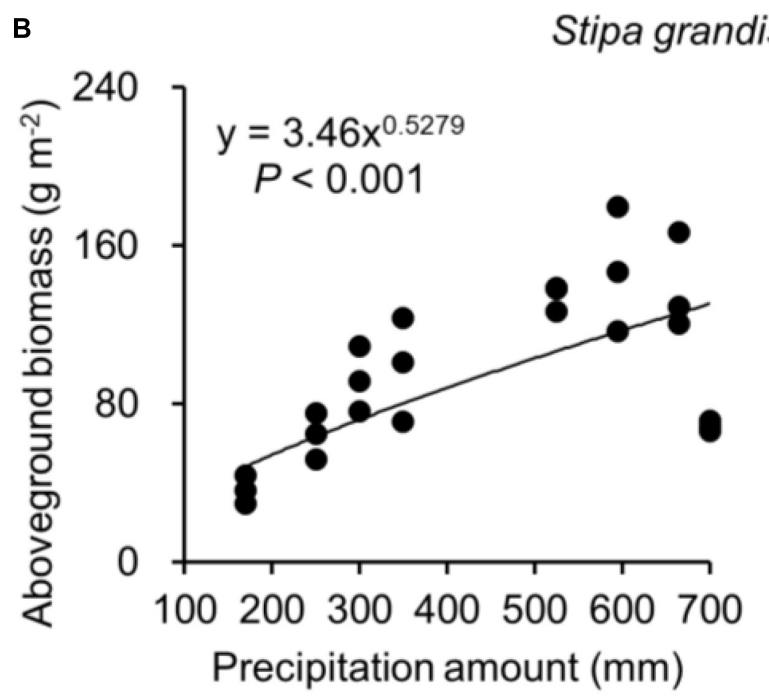

D

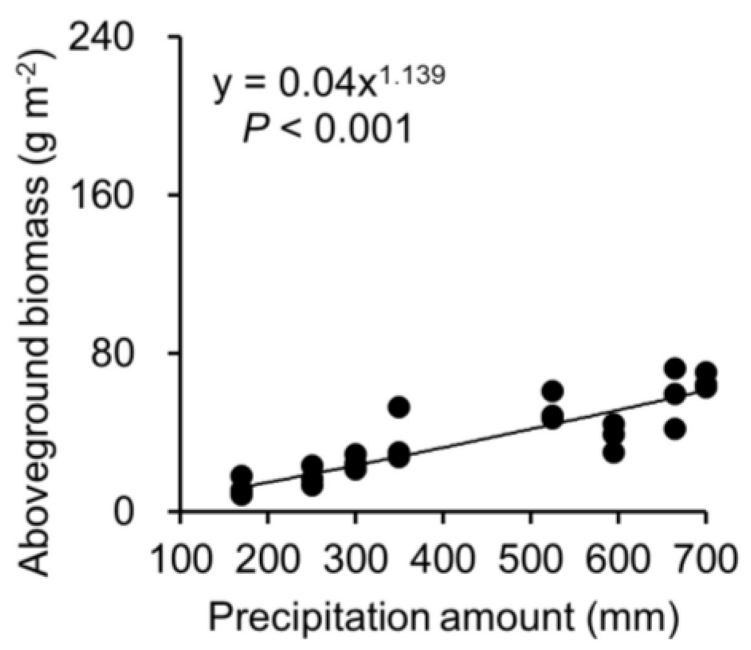

FIGURE 2 | At the pot scale, regressions between precipitation amount and aboveground biomass, separately for (A) Leymus chinensis, (B) Stipa grandis, (C) Artemisia frigida, and (D) Potentilla acaulis.

S. grandis (Figure 5B), while it increased the B:A ratio of L. chinensis (Figure 5A), decreased for $P$. acaulis, and seemingly first decreased and then increased for A. frigida (with a threshold around $475 \mathrm{~mm}$ ). A greater $\mathrm{B}: \mathrm{A}$ ratio suggests a greater biomass investment in the belowground organs.

Aboveground biomass was positively correlated with belowground biomass for all four target species, as expected (Figure 6). The slopes of the relationship between logaboveground biomass and log-belowground biomass for L. chinensis, $S$. grandis, A. frigida, and $P$. acaulis were 1.25, 0.90, 0.49 , and 0.53 , respectively. These values differed significantly from 1.0 for three species $(P=0.001,<0.001$, and $<0.001$ for L. chinensis, $A$. frigida, and $P$. acaulis, respectively), indicating non-isometric growth for these rhizome or stolon-forming species. The relationship did not differ significantly from the 1:1 line for $S$. grandis $(P=0.275)$.

\section{DISCUSSION}

In this study, we subjected four species common in grasslands of Inner Mongolia to a precipitation gradient. In general, we found that both aboveground biomass and belowground biomass production was stimulated as growing season precipitation was increased. This was unsurprising, given that these grasslands are known to be precipitation-limited (Kang et al., 2011; Guo et al., 2015). The focus in the current study was primarily on biomass allocation patterns, which we considered by testing three hypotheses. The first hypothesis stated that species with 

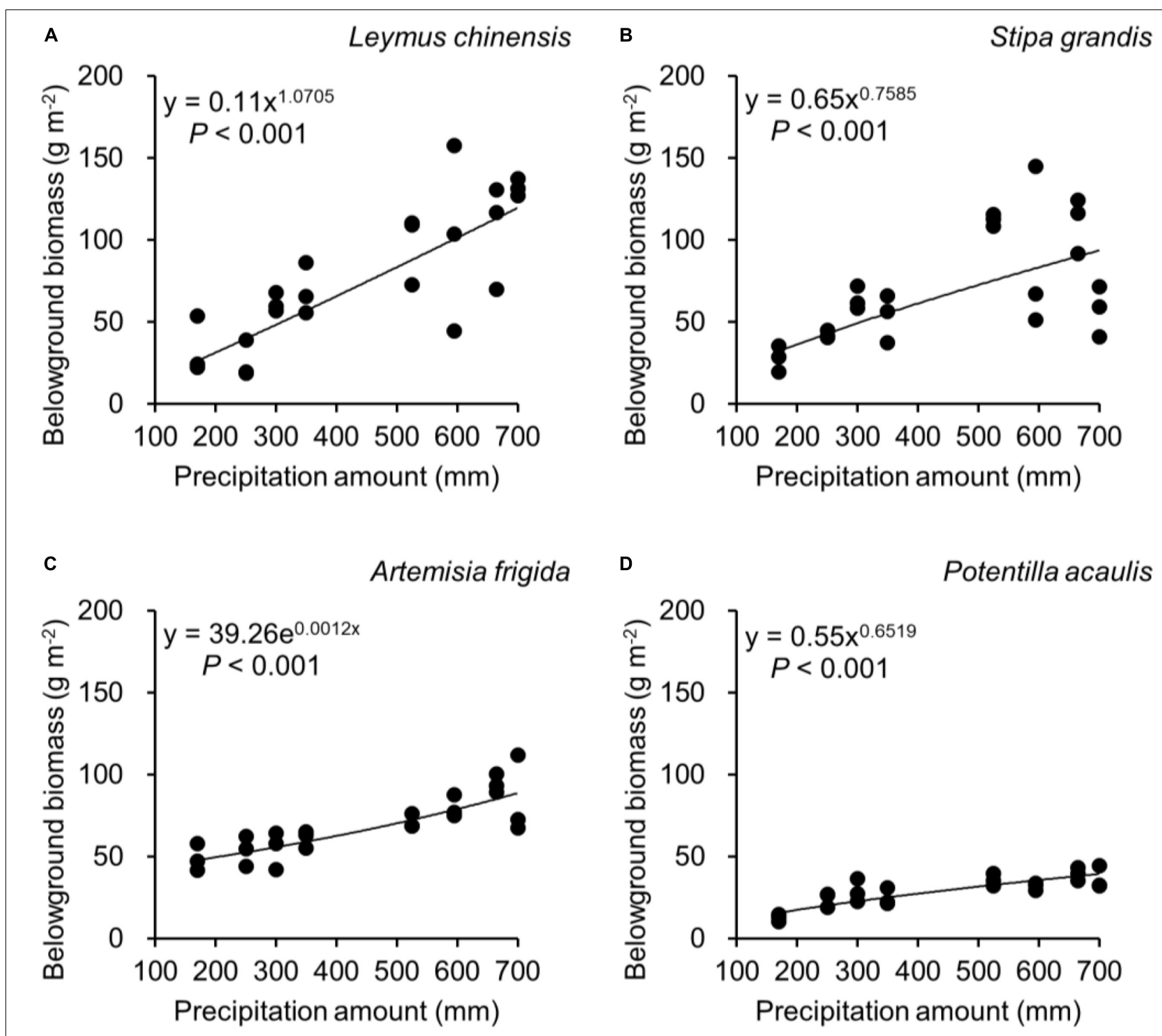

D

Potentilla acaulis

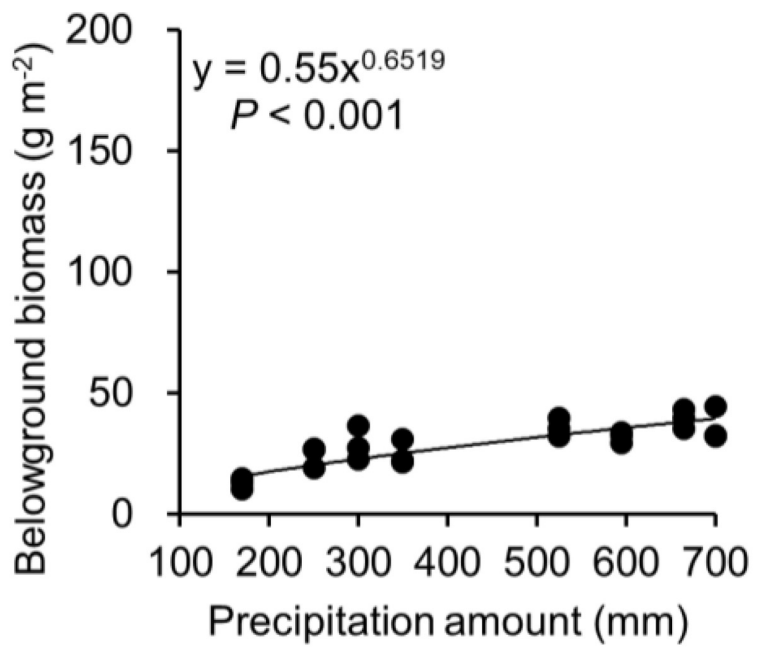

FIGURE 3 | At the pot scale, regressions between precipitation amount and belowground biomass, separately for (A) Leymus chinensis, (B) Stipa grandis, (C) Artemisia frigida, and (D) Potentilla acaulis.

rhizomes or stolons would allocate more biomass belowground. This pattern was only found for one rhizome and stolon forming species, namely L. chinensis. The other two such species, A. frigida and $P$. acaulis, displayed similar allocation patterns with the non-rhizome or stolon forming S. grandis. It should be noted that in contrast to studies calculating biomass allocation based on root biomass (e.g., Berendse and Möller, 2009), we considered the complete belowground biomass, including roots, rhizomes, and stolons.

The second hypothesis studied here, assumed that biomass allocation of species with rhizomes or stolons would increase along the precipitation gradient. This was not convincingly supported, with different patterns between precipitation amount and $\mathrm{B}: \mathrm{A}$ ratios being observed for the four target plant species.
Specifically, the B:A ratio of non-rhizome or stolon forming $S$. grandis remained constant along the precipitation gradient, suggesting that the biomass allocation of this species was not sensitive to precipitation amount. In line with our expectations, a positive pattern was found in L. chinensis, which could be explained by the fact that $L$. chinensis has a strong forage ability as a rhizomatous species (Wang et al., 2004), which enables it to allocate more biomass to roots when growing in wet conditions (Yang and Yang, 1998). Similar patterns were also found in species such as Salix psammophila, Hedysarum leave, Artemisia ordosica, and Caragana korshinskii (Dong et al., 1999; Xiao et al., 2001). Nevertheless, a contrasting (negative) pattern was apparent for $P$. acaulis, indicating more biomass was allocated aboveground with increasing precipitation amount. Interestingly, our data 

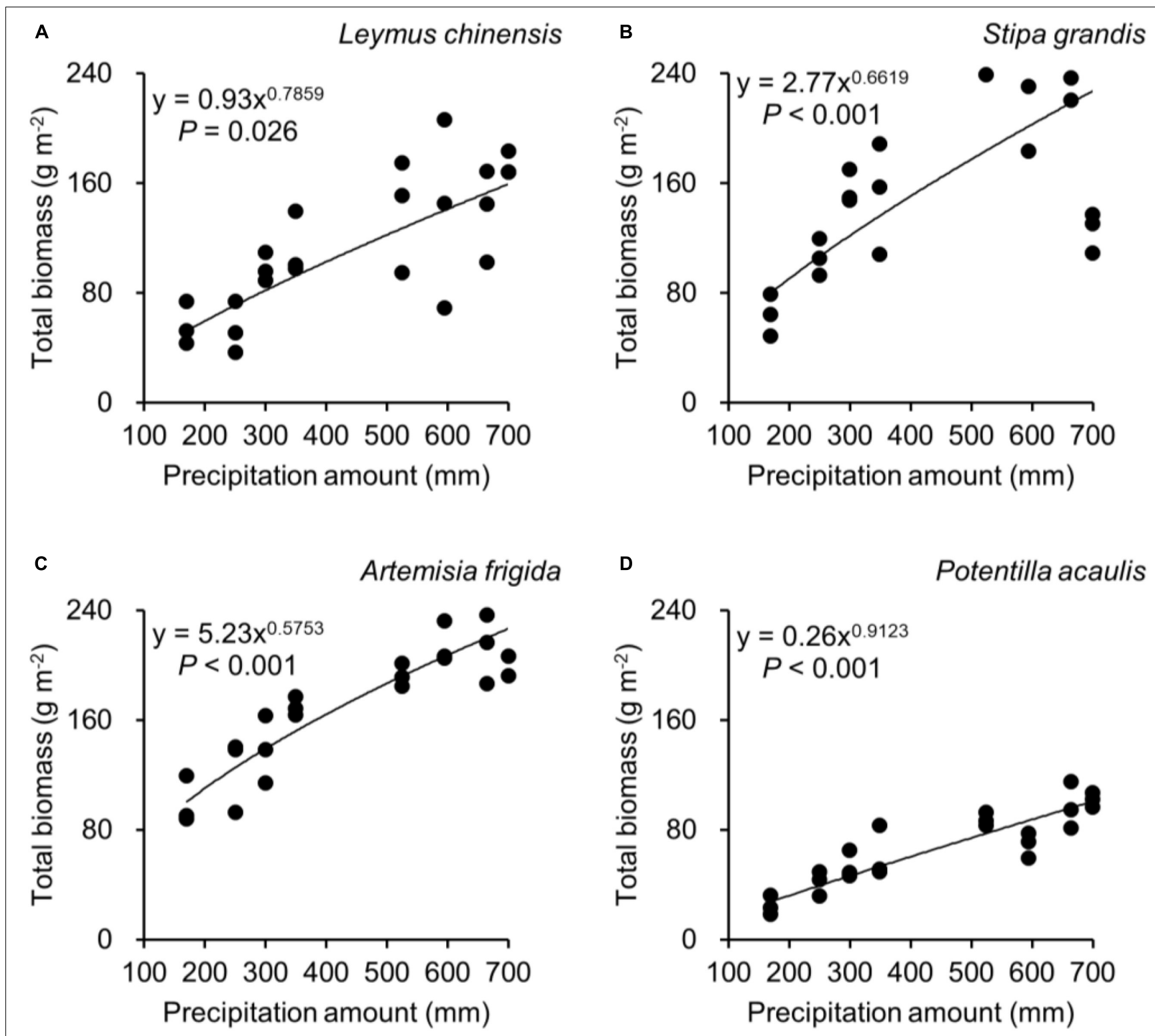

FIGURE 4 | At the pot scale, regressions between precipitation amount and total biomass, separately for (A) Leymus chinensis, (B) Stipa grandis, (C) Artemisia frigida, and (D) Potentilla acaulis.

suggested a unimodal pattern between precipitation amount and $\mathrm{B}$ :A ratio for $A$. frigida, with higher precipitation only increasing the biomass allocation belowground up to a certain point.

According to isometric partitioning, aboveground biomass and belowground biomass would be isometric at the species scale (hypothesis 3). This would suggest both no changes in B:A ratios along the precipitation gradient and no deviation from 1:1 lines in the aboveground biomass vs. belowground biomass relationship. Our results suggest that only $S$. grandis seemed to respond in line with isometric partitioning. The three rhizome or stolonforming species did not adhere to isometric partitioning, with both asymmetrical variation between aboveground biomass and belowground biomass, in contrast with Enquist and Niklas (2002) and Yang et al. (2009), as well as differences in B:A ratios along the precipitation gradient. Regarding the allometric relationships between aboveground biomass and belowground biomass, the average slope of the four target plant species was 0.79 , which is in line with the global grasslands' slope (i.e., 0.72, Wang et al., 2014), but smaller than China's grasslands' slope (i.e., 1.05, Wang et al., 2014). Such differences may be caused by the limited number of plant species used in this study, and because we explored allometric partitioning at the species scale, not at the individual or the community scale like in previous studies (Enquist and Niklas, 2002; Wang et al., 2010, 2014).

Biomass allocation between belowground biomass and aboveground biomass differed among species in our study, 


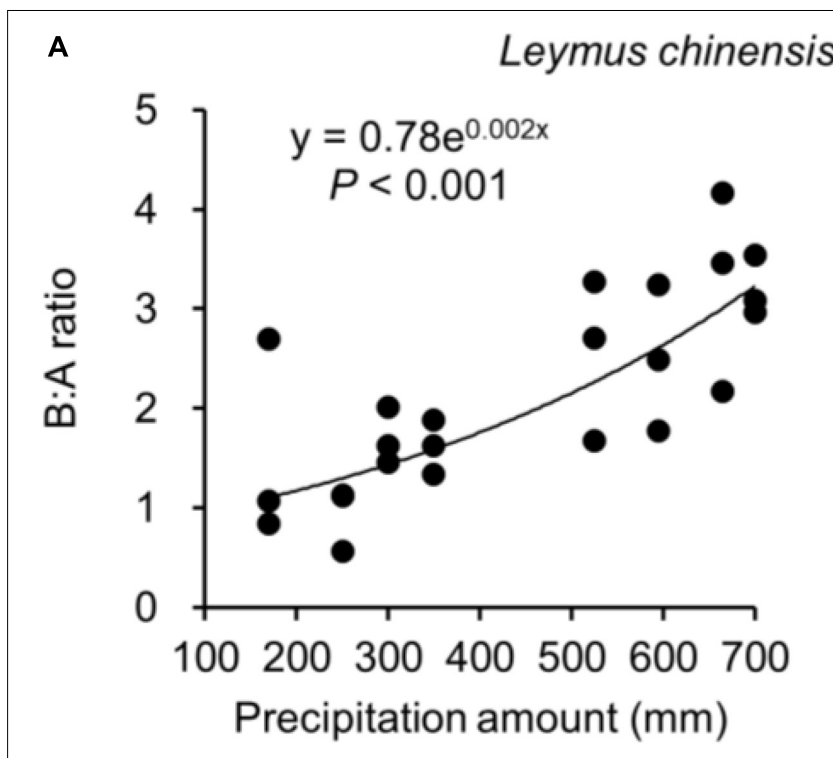

B

Stipa grandis

c

Artemisia frigida

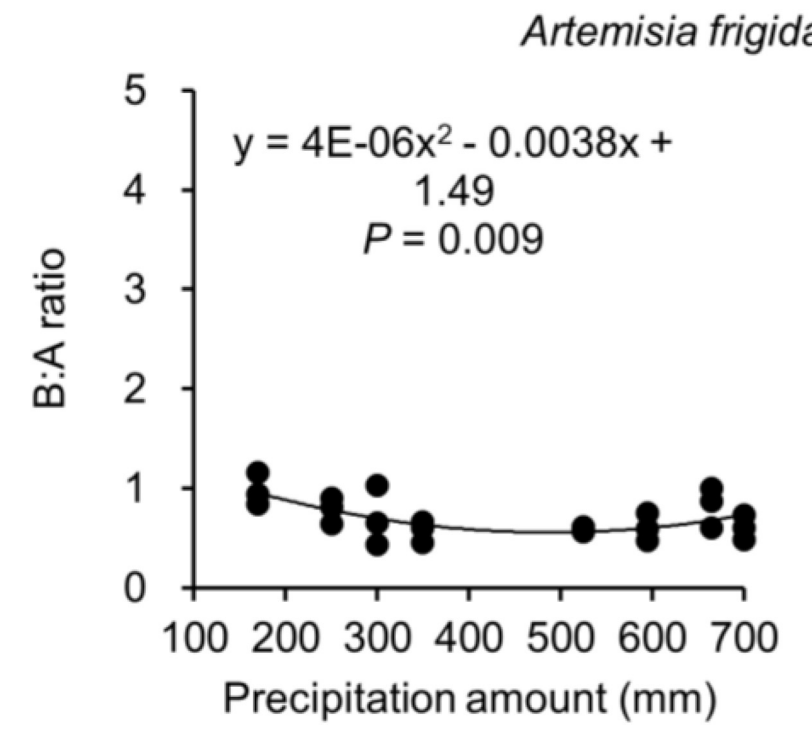

FIGURE 5 | At the pot scale, regressions between precipitation amount and B:A ratio (i.e., ratio of belowground biomass and aboveground biomass), separately for (A) Leymus chinensis, (B) Stipa grandis, (C) Artemisia frigida, and (D) Potentilla acaulis, where each dot refers to a B:A ratio from a pot.

in line with previous findings ( $\mathrm{Ma}$ et al., 2008; Kang et al., 2013; Gong et al., 2015; Zhang et al., 2019). Mokany et al. (2006) suggested that the root/shoot (R/S) ratio in grasslands tends to decrease with increasing MAP. However, Yang et al. (2010) reported that the $\mathrm{R} / \mathrm{S}$ ratio in China's grasslands did not show any significant pattern along increasing MAP. Several potential causes were proposed, relating to climatic factors (e.g., MAT and MAP). The plant species used in our experiment, which are dominant species in the Inner Mongolia steppe, displayed various relationships between B:A (similar to $\mathrm{R} / \mathrm{S}$ ) ratio and precipitation amount. Plant communities with species responding differently regarding biomass allocation, e.g., in an opposite direction, to precipitation may see little
D
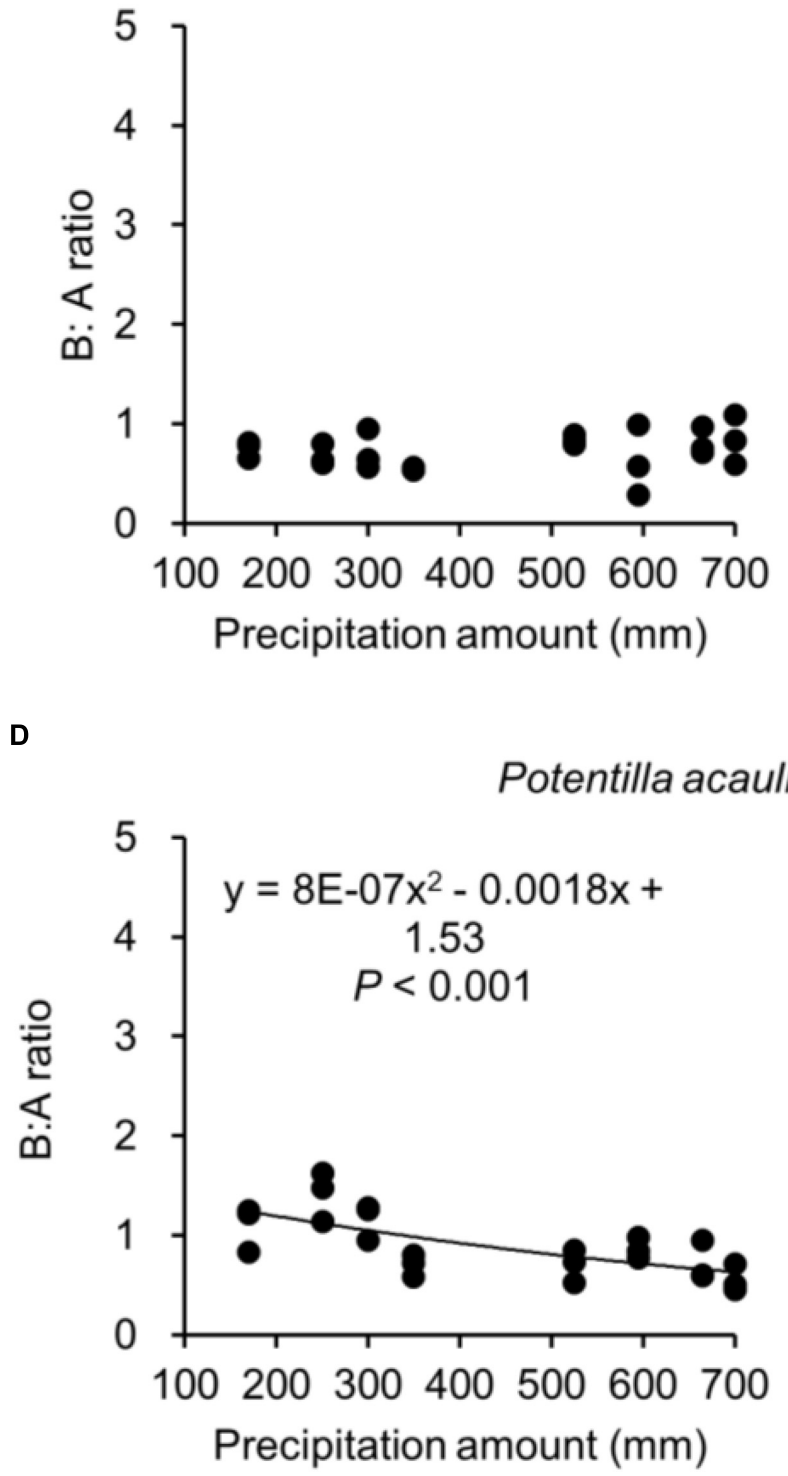

Potentilla acaulis

total effect at the community scale. Nevertheless, the speciesspecific changes in allocation patterns could lead to different competitive outcomes (Aerts et al., 1991), thus changing species composition in the longer term, and thus the B:A (or R: S) ratio of the community.

Results of this study should be interpreted and extrapolated with caution for a number of reasons. First, the experiment was short term, featuring a limited number of species. Studying longer term effects on more species would allow more extensive generalization. Furthermore, two species in this study were sown at the beginning of the experiment, while the other two were transplanted from local grasslands. It is possible that plant age affects allocation patterns, with for example Yu et al. (2019) 
TABLE 2 | Results of the curve estimation of the relationships between precipitation amount and aboveground biomass, belowground biomass, total biomass, and B:A ratio (i.e., ratio of belowground biomass and aboveground biomass) of Leymus chinensis, Stipa grandis, Artemisia frigida, and Potentilla acaulis with linear, quadratic, power, and exponential equations, where AIC, F, df, and P value were showed.

\begin{tabular}{|c|c|c|c|c|c|c|c|c|c|c|c|c|c|c|c|c|}
\hline & \multicolumn{4}{|c|}{ Aboveground biomass } & \multicolumn{4}{|c|}{ Belowground biomass } & \multicolumn{4}{|c|}{ Total biomass } & \multicolumn{4}{|c|}{ B:A ratio } \\
\hline & AIC & $F$ & df & $P$ & AIC & $F$ & Df & $P$ & AIC & $F$ & df & $P$ & AIC & $F$ & df & $P$ \\
\hline \multicolumn{17}{|c|}{ Leymus chinensis Equation } \\
\hline Linear & 116.2 & 3.1 & 1.22 & 0.094 & 155.1 & 45.5 & 1.22 & $<0.001$ & 168.0 & 33.2 & 1.22 & $<0.001$ & -19.6 & 32.240 & 1.22 & $<0.001$ \\
\hline Quadratic & 111.5 & 4.0 & 2.21 & 0.033 & 155.0 & 21.8 & 2.21 & $<0.001$ & 167.1 & 16.74 & 2.21 & $<0.001$ & -20.8 & 16.650 & 2.21 & $<0.001$ \\
\hline Power & -56.2 & 5.7 & 1.22 & 0.026 & -43.2 & 41.9 & 1.22 & $<0.001$ & -54.7 & 36.4 & 1.22 & $<0.001$ & -48.0 & 26.391 & 1.22 & $<0.001$ \\
\hline Exponential & -54.6 & 4.0 & 1.22 & 0.061 & -41.7 & 38.0 & 1.22 & $<0.001$ & -52.5 & 31.3 & 1.22 & $<0.001$ & -50.1 & 30.641 & 1.22 & $<0.001$ \\
\hline \multicolumn{17}{|c|}{ Stipa grandis Equation } \\
\hline Linear & 171.4 & 11.8 & 1.22 & 0.002 & 161.4 & 13.3 & 1.22 & 0.001 & 194.9 & 15.4 & 1.22 & 0.001 & -79.5 & 1.2 & 1.22 & 0.285 \\
\hline Quadratic & 154.9 & 21.6 & 2.21 & $<0.001$ & 155.1 & 11.5 & 2.21 & $<0.001$ & 180.4 & 22.1 & 2.21 & $<0.001$ & -81.0 & 1.3 & 2.21 & 0.284 \\
\hline Power & -49.1 & 23.0 & 1.22 & $<0.001$ & -46.4 & 24.0 & 1.22 & $<0.001$ & -52.1 & 28.6 & 1.22 & $<0.001$ & -57.1 & 0.2 & 1.22 & 0.655 \\
\hline Exponential & -43.4 & 13.5 & 1.22 & 0.001 & -42.3 & 16.8 & 1.22 & $<0.001$ & -46.1 & 17.4 & 1.22 & $<0.001$ & -57.4 & 0.5 & 1.22 & 0.504 \\
\hline \multicolumn{17}{|c|}{ Artemisia frigida Equation } \\
\hline Linear & 144.0 & 48.5 & 1.22 & $<0.001$ & 114.2 & 49.4 & 1.22 & $<0.001$ & 149.6 & 91.4 & 1.22 & $<0.001$ & -78.5 & 3.0 & 1.22 & 0.095 \\
\hline Quadratic & 137.9 & 32.9 & 2.21 & $<0.001$ & 113.9 & 24.0 & 2.21 & $<0.001$ & 146.1 & 52.2 & 2.21 & $<0.001$ & -86.0 & 5.9 & 2.21 & 0.009 \\
\hline Power & -74.6 & 60.8 & 1.22 & $<0.001$ & -88.3 & 48.4 & 1.22 & $<0.001$ & -95.1 & 104.9 & 1.22 & $<0.001$ & -63.8 & 4.3 & 1.22 & 0.051 \\
\hline Exponential & -68.2 & 41.4 & 1.22 & $<0.001$ & -90.1 & 53.9 & 1.22 & $<0.001$ & -88.5 & 74.6 & 1.22 & $<0.001$ & -62.1 & 2.5 & 1.22 & 0.127 \\
\hline \multicolumn{17}{|c|}{ Potentilla acaulis Equation } \\
\hline Linear & 112.3 & 68.9 & 1.22 & $<0.001$ & 83.8 & 41.3 & 1.22 & $<0.001$ & 124.1 & 86.1 & 1.22 & $<0.001$ & -67.2 & 19.7 & 1.22 & $<0.001$ \\
\hline Quadratic & 112.2 & 33.1 & 2.21 & $<0.001$ & 79.6 & 25.5 & 2.21 & $<0.001$ & 122.8 & 43.8 & 2.21 & $<0.001$ & -67.4 & 9.5 & 2.21 & $<0.001$ \\
\hline Power & -60.2 & 96.2 & 1.22 & $<0.001$ & -73.9 & 55.7 & 1.22 & $<0.001$ & -73.3 & 106.5 & 1.22 & $<0.001$ & -62.0 & 19. 1 & 1.22 & $<0.001$ \\
\hline Exponential & -54.2 & 70.0 & 1.22 & $<0.001$ & -66.8 & 35.8 & 1.22 & $<0.001$ & -64.8 & 68.3 & 1.22 & $<0.001$ & -62.7 & 20.4 & 1.22 & $<0.001$ \\
\hline
\end{tabular}

A better estimation (marked in red) is determined by a smaller AIC (Akaike Information Criterion) and a significant $P$ value (marked in bold). 

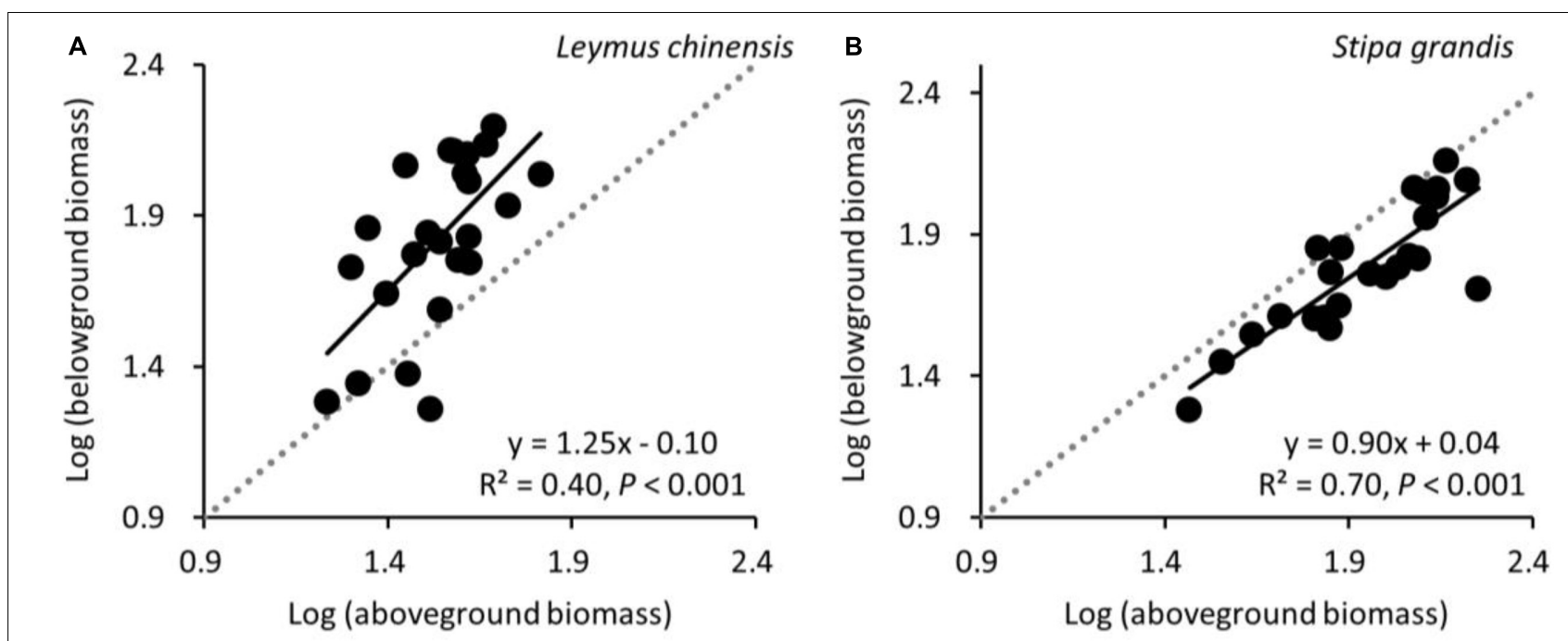

C

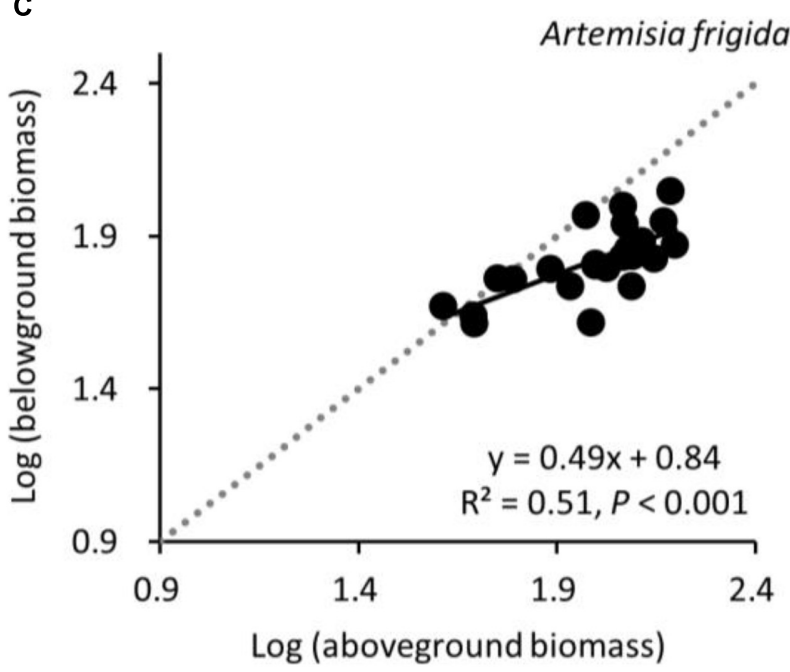

D

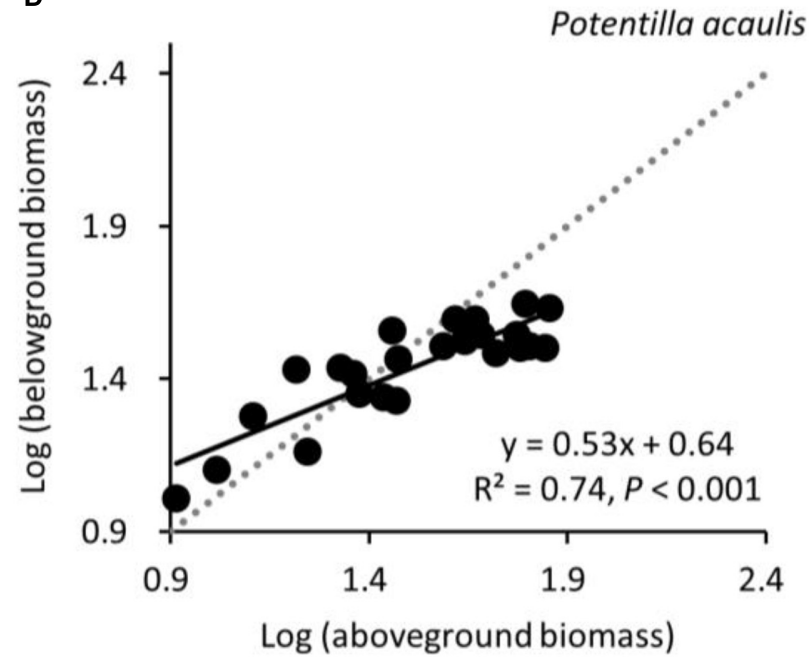

FIGURE 6 | At the pot scale, allometric relationships between log-transformed aboveground biomass and long-transformed belowground biomass for (A) Leymus chinensis, (B) Stipa grandis, (C) Artemisia frigida, and (D) Potentilla acaulis. The 1:1 line (dotted) is added for clarity.

reporting that resource limitation could be partially the reason of decreasing allocation with age, where resources such as nutrients and waters become limited with plant grow (age). Moreover, we allowed intraspecific competition in our study, which is realistic, but which would also alter allocation patterns (Yang et al., 2019). Comparisons with experiments considering individual plants (e.g., Lamb et al., 2007), are thus not straightforward. Another factor to consider in future studies is soil heterogeneity. Plants may allocate more biomass to roots when growing in higher levels of soil heterogeneity (James et al., 2003; Michael and Elizabeth, 2004; Hagiwara et al., 2010; Wu et al., 2014; Liu et al., 2017a), and plants growing on low-nutrient patches have been reported to grow more roots into their neighboring high-nutrient patches (Liu et al., 2017b, 2019).

In sum, in our experiment we found that changes in precipitation affected biomass allocation in general, but that significant species-specific differences were apparent. Increasing precipitation increased the biomass allocation to belowground organs for one species with rhizomes or stolons, while it did not impact the biomass allocation of the non-rhizomes or stolon-forming species in our study. Isometric partitioning, meaning constant allocation of biomass aboveground and belowground regardless of plant size or precipitation amounts, seemed to occur for one species, but not for the rhizome or stolon-forming ones. Increased knowledge of allocation patterns leads to improved understanding of the structure and functioning of grasslands under changes in the environment, such as altered precipitation. Moreover, changed allocation patterns matter as they can affect agricultural value, carbon sequestration, and climate resilience. The results of our study could be used as a basis for further research into allocation patterns in a changing environment, spanning a wider range of species, and explicitly considering consequences for ecosystem services. 


\section{DATA AVAILABILITY STATEMENT}

The original contributions presented in the study are included in the article/supplementary material, further inquiries can be directed to the corresponding author.

\section{AUTHOR CONTRIBUTIONS}

ZL designed and conducted the study. YL and ZL analyzed the data. All authors discussed the data and contributed crucially to the drafts.

\section{REFERENCES}

Achten, W. K. J., Maes, W. H., Reubens, B., Mathijs, E., Singh, V. P., Verchot, L., et al. (2010). Biomass production and allocation in Jatropha curcas L. seedling under different levels of drought stress. Biomass Bioenergy 34, 667-676. doi: 10.1016/j.biombioe.2010.01.010

Aerts, R., Boot, R. G. A., and Vanderaart, P. J. M. (1991). The relation between aboveground and belowground biomass allocation patterns and competitive ability. Oecologia 87, 551-559. doi: 10.1007/BF00320419

Arnbjerg-Nielsen, K., Willems, P., Olsson, J., Beecham, S., Pathirana, A., Gregersen, I. B., et al. (2013). Impacts of climate change on rainfall extremes and urban drainage systems: a review. Water Sci. Technol. 68, 16-28. doi: 10.2166/wst. 2013.251

Bai, Y., Wu, J., Clark, C. M., Pan, Q., Zhang, L., Chen, S., et al. (2012). Grazing alters ecosystem functioning and C:N:P stoichiometry of grasslands along a regional precipitation gradient. J. Appl. Ecol. 49, 1204-1215. doi: 10.1111/j.1365-2664. 2012.02205.x

Bai, Y., Wu, J., Xing, Q., Pan, Q., Huang, J., Yang, D., et al. (2008). Primary production and rain use efficiency across a precipitation gradient on the Mongolia plateau. Ecology 89, 2140-2153. doi: 10.1890/07-0992.1

Bai, Y., and Xu, Z. (1997). A model of aboveground biomass of Aneurolepidium chinense community in response to seasonal precipitation. Acta Pratacult. Sin. $6,1-6$.

Berendse, F., and Möller, F. (2009). Effects of competition on root-shoot allocation in Plantago lanceolate L.: adaptive plasticity or ontogenetic drift? Plant Ecol. 201, 567-573. doi: 10.1007/s11258-008-9485-z

Bloom, A. J., Chapin, F. S., and Mooney, H. A. (1985). Resource limitation in plants-an economic analogy. Annu. Rev. Ecol. Systemat. 16, 363-392. doi: 10.1146/annurev.es.16.110185.002051

Cai, X., Li, Z., Chen, Z., Wang, Y., Wang, S., and Wang, Y. (2005). The relationship between aboveground biomass and precipitation on Stipa grandis steppe in Inner Mongolia. Acta Ecol. Sin. 25, 1657-1662.

Chen, G., Zhao, W., He, S., and Fu, X. (2016). Biomass allocation and allometric relationship in aboveground components of Salix psammophila branches. J. Desert Res. 36, 357-363.

Cheng, D. L., and Niklas, K. J. (2007). Above- and below-ground biomass relationships across 1534 forested communities. Ann. Bot. 99, 95-102. doi: $10.1093 / \mathrm{aob} / \mathrm{mcl} 206$

Chu, C., Bartlett, M., Wang, Y., He, F., Weiner, J., Chave, J., et al. (2016). Does climate directly influence NPP globally? Glob. Change Biol. 22, 12-24. doi: $10.1111 /$ gcb.13079

Cottingham, K. L., Lennon, J. T., and Brown, B. L. (2005). Knowing when to draw the line: designing more information ecological experiments. Front. Ecol. Environ. 3, 145-152. doi: 10.1890/1540-9295(2005)003[0145:kwtdtl]2. $0 . \operatorname{co} ; 2$

Dong, M., Alateng, B., Xing, X., and Wang, Q. (1999). Genet features and ramet population features in the rhizomatous grass species Psammochloa villosa. Acta Phytoecol. Sin. 23, 302-310.

Enquist, B. J., and Niklas, J. (2002). Global allocation rules for patterns of biomass partitioning in seed plants. Science 295, 1517-1520. doi: 10.1126/science. 1066360

\section{FUNDING}

YL holds a fund from the National Key Research and Development Program of China (2019YFC0507704) and a start-up fund from Lanzhou University (508000-561119213). This research was supported by the National Natural Science Foundation of China (41571505).

\section{ACKNOWLEDGMENTS}

We acknowledge Jinhua Li for the experimental assistance.

Eziz, A., Yan, Z., Tian, D., Han, W., Tang, Z., and Fang, J. (2017). Drought effect on plant biomass allocation: a meta-analysis. Ecol. Evol. 7, 11002-11010. doi: 10.1002/ece3.3630

Falster, D. S., Warton, D. I., and Wright, I. J. (2006). User's Guide to SMATR: Standardised Major Axis Tests and Routines: Version 2.0.

Fan, J., Wang, K., Harris, W., Zhong, H., Hu, Z., Han, B., et al. (2009). Allocation of vegetation biomass across a climate-related gradient in the grasslands of Inner Mongolia. J. Arid Environ. 73, 521-528. doi: 10.1016/j.jaridenv.2008. 12.004

Felton, A. J., Slette, I. J., Smith, M. D., and Knapp, A. K. (2019). Precipitation amount and event size interact to reduce ecosystem functioning during dry years in a mesic grassland. Glob. Change Biol. 26, 658-668. doi: $10.1111 / \mathrm{gcb}$. 14789

Gedroc, J. J., McConnaughay, D. M., and Coleman, J. S. (1996). Plasticity in root/shoot partitioning: optimal, ontogenetic, or both? Funct. Ecol. 10, 44-50. doi: $10.2307 / 2390260$

Gherardi, L. A., and Sala, O. E. (2019). Effect of interannual precipitation variability on dryland productivity: a global synthesis. Glob. Change Biol. 25, 269-276. doi: $10.1111 /$ gcb. 14480

Gong, X., Fanselow, N., Dittert, K., Taube, F., and Lin, S. (2015). Response of primary production and biomass allocation to nitrogen and water supplementation along a grazing intensity gradient in semiarid grassland. Eur. J. Agron. 63, 27-35. doi: 10.1016/j.eja.2014.11.004

Gonzalez-Dugo, V., Durand, J. L., and Gastal, F. (2010). Water deficit and nitrogen nutrition of crops. A review. Agron. Sustain. Dev. 30, 529-544. doi: 10.1051/ agro/2009059

Guo, Q., Hu, Z., Li, S., Yu, G., Sun, X., Zhang, L., et al. (2015). Contrasting responses of gross primary productivity to precipitation events in a waterlimited and a temperature-limited grassland ecosystem. Agric. For. Meteorol. 214-215, 169-177. doi: 10.1016/j.agrformet.2015.08.251

Hagiwara, Y., Kachi, N., and Suzuki, J. I. (2010). Effects of temporal heterogeneity of water supply on the growth of Perilla frutescens depend on plant density. Ann. Bot. 106, 173-181. doi: 10.1093/aob/mcq096

Herrero, M., Havlik, P., Valin, H., Notenbaert, A., Rufino, M. C., Thornton, P. K., et al. (2013). Biomass use, production, feed efficiencies and greenhouse gas emissions from global livestock systems. Proc. Natl. Acad. Sci. U.S.A. 110, 20888-20893. doi: 10.1073/pnas.1308149110

Huang, Y., Sun, W., Zhang, W., Yu, Y., and Wei, Y. (2010). Study on carbon budget in grassland of China: progress and perspectives. Quatern. Sci. 30, 456-465.

Hyun, S. H., and Yeh, S. W. (2020). Characteristics of internal variability on summer rainfall in Northeast Asia in a changing climate. Clim. Dyn. 54, 1179-1195. doi: 10.1007/s00382-019-05051-1

James, S. E., Pärtel, M., Wilson, S. D., and Peltzer, D. A. (2003). Temporal heterogeneity of soil moisture in grassland forest. J. Ecol. 91, 234-239. doi: 10.1046/j.1365-2745.2003.00758.x

Jia, B., Zhou, G., Wang, F., and Wang, Y. (2005). Soil respiration and its influencing factors at grazing and fenced typical Leymus chinensis Steppe, ei Monggol. Environ. Sci. 26, 1-7.

Kang, M., Dai, C., Ji, W., Jiang, Y., Yuan, Z., and Chan, H. (2013). Biomass and its allocation in relation to temperature, precipitation, and soil nutrients 
in Inner Mongolia grasslands. PLoS One 8:e69561. doi: 10.1371/journal.pone. 0069561

Kang, X., Hao, Y., Li, C., Cui, X., Wang, J., Rui, Y., et al. (2011). Modelling impacts of climate change on carbon dynamics in s steppe ecosystem in Inner Mongolia, China. J. Soils Sedim. 11, 562-576. doi: 10.1007/s11368-0110339-2

Kayler, Z. E., De Boeck, H. J., Fatichi, S., Grünzweig, J. M., Merbold, L., Beier, C., et al. (2015). Experiments to confront the environmental extremes of climate change. Front. Ecol. Environ. 13:219-225. doi: 10.1890/ 140174

Kreyling, J., Khan, M. A. S. A., Sultana, F., Babel, W., Beierkuhnlein, C., Foken, T., et al. (2017). Drought effects in climate change manipulation experiments: quantifying the influence of ambient weather conditions and rain-out shelter artifacts. Ecosystems 20, 301-315. doi: 10.1007/s10021-0160025-8

Lamb, E. G., Shore, B. H., and Cahill, J. F. (2007). Water and nitrogen addition differentially impact plant competition in a native rough fescue grassland. Plant Ecol. 192, 21-33. doi: 10.1007/s11258-006-9222-4

Li, J., and Li, Z. (2002). Clonal morphological plasticity and biomass allocation pattern of Artemisia frigida and Potentilla acaulis under different grazing intensities. Acta Phytoecol. Sin. 26, 435-440.

Li, J., Li, Z., and Ren, J. (2005). Effect of grazing intensity on clonal morphological plasticity and biomass allocation patterns of Artemisia frigida and Potentilla acaulis in the Inner Mongolia steppe. N. Z. J. Agric. Res. 48, 57-61. doi: 10.1080/00288233.2005.9513631

Liu, Y., Bortier, M. F., De Boeck, H. J., and Nijs, I. (2017a). Root distribution responses to three-dimensional soil heterogeneity in experimental mesocosms. Plant Soil 421, 353-366. doi: 10.1007/s11104-017-3472-x

Liu, Y., De Boeck, H. J., Li, Z., and Nijs, I. (2019). Unimodal relationship between three-dimensional soil heterogeneity and plant species diversity in experimental mesocosms. Plant Soil 436, 397-411. doi: 10.1007/s11104-01903938-w

Liu, Y., De Boeck, H. J., Wellens, M. J., and Nijs, I. (2017b). A simple method to vary soil heterogeneity in three dimensions in experimental mesocosms. Ecol. Res. 32, 27-295. doi: 10.1007/s11284-017-1435-6

Liu, Z., Chen, R., Song, Y., and Han, C. (2015). Aboveground biomass and water storage allocation in alpine willow shrubs in the Qilian Mountains in China. J. Mount. Sci. 12, 207-217. doi: 10.1007/s11629-013-2784-4

Liu, Z., Li, Z., Dong, M., Ivan, N., Jan, B., and El-Bana, M. I. (2007). Small-scale spatial associations between Artemisia frigida and Potentilla acaulis at different intensities of sheep grazing. Appl. Veget. Sci. 10, 139-148. doi: 10.1658/14022001(2007)10[139:SSABAF]2.0.CO;2

Liu, Z., Li, Z., Dong, M., and Johnston, B. (2006). The response of a shrub-invaded grassland on the Inner Mongolia steppe to long-term grazing by sheep. N. Z. J. Agric. Res. 49, 163-174. doi: 10.1080/00288233.2006.9513706

Lv, X., Zhou, G., Wang, Y., and Song, X. (2016). Sensitive indicators of zonal Stipa species to changing temperature and precipitation in Inner Mongolia grassland. China. Front. Plant Sci. 7:73. doi: 10.3389/fpls.2016.00073

Ma, W., Yang, Y., He, J., Zeng, H., and Fang, J. (2008). Above- and belowground biomass in relation to environmental factors in temperate grasslands, Inner Mongolia. Sci. China Ser. C-Life Sci. 51, 263-270. doi: 10.1007/s11427-0080029-5

Ma, X., and Wang, X. (2021). Aboveground and belowground biomass and its' Allometry for Salsola passerina shrub in degraded steppe desert in Northwestern China. Land Degrad. Dev. 32, 714-722. doi: 10.1002/ldr. 3772

Mao, W., Allington, G., Li, Y., Zhang, T., Zhao, X., and Wang, S. (2012). Life history influences biomass allocation in response to limiting nutrients and water in an arid system. Polish J. Ecol. 60, 545-557.

Maryol, E., and Lin, C. (2015). Evaluation of atmospheric $\mathrm{CO}_{2}$ sequestration by alkaline soils through simultaneous enhanced carbonation and biomass production. Geoderma 241, 24-31. doi: 10.1016/j.geoderma.2014. 10.015

Maurer, G. E., Hallmark, A. J., Brown, R. F., Sala, O. E., and Collins, S. L. (2020). Sensitivity of primary production to precipitation across the United States. Ecol. Lett. 23, 527-536. doi: 10.1111/ele.13455

Meng, B., Shi, B., Zhong, S., Chai, H., Li, S., Wang, Y., et al. (2019). Drought sensitivity of aboveground productivity in Leymus chinensis meadow steppe depends on drought timing. Oecologia 191, 685-696. doi: 10.1007/s00442-01904506-w

Michael, H. J., and Elizabeth, J. A. (2004). The effects of environmental heterogeneity on root growth and root/shoot partitioning. Annu. Bot. 94, 1-8. doi: $10.1093 / \mathrm{aob} / \mathrm{mch} 111$

Michaletz, S. T., Kerkhoff, A. J., and Enquist, B. J. (2018). Drivers of terrestrial plant production across broad geographical gradients. Glob. Ecol. Biogeogr. 27, 166-174. doi: 10.1111/geb.12685

Milchunas, D. G., Mosier, A. R., Morgan, J. A., LeCain, D. R., King, J. Y., and Nelson, J. A. (2005). Root production and tissue quality in a shortgrass steppe exposed to elevated $\mathrm{CO}_{2}$ : using a new ingrowth method. Plant Soil 268, 111-122. doi: 10.1007/s11104-004-0230-7

Mokany, K., Raison, R. J., and Prokushkin, A. S. (2006). Critical analysis of root: shoot ratios in terrestrial biomes. Glob. Change Biol. 12, 84-96. doi: 10.1111/j. 1365-2486.2005.001043.x

Niklas, K. J. (2005). Modelling below- and above-ground biomass for non-woody and woody plants. Ann. Bot. 95, 315-321. doi: 10.1093/aob/mci028

Ohba, M., and Sugimoto, S. (2019). Differences in climate change impacts between weather patterns: possible effects on spatial heterogeneous changes in future extreme rainfall. Clim. Dyn. 52, 4177-4191. doi: 10.1007/s00382-018-4374-1

Pan, Q., Bai, Y., Han, X., and Yang, J. (2005). Effects of nitrogen on a Leymus chinensis population in typical steppe of Inner Mongolia. Chinese J. Plant Ecol. 2, 311-317. doi: 10.17521/cjpe.2005.0040

Parton, W., Morgan, J., Smith, D., Del Grosso, S., Prihodko, L., LeCain, D., et al. (2012). Impact of precipitation dynamics on net ecosystem productivity. Glob. Change Biol. 18, 915-927. doi: 10.1111/j.1365-2486.2011.02611.x

Poorter, H., Buhler, J., van Dusschoten, D., Climent, J., and Postma, J. A. (2012a). Pot size matters: a meta-analysis of the effects of rooting volume on plant growth. Funct. Plant Biol. 39, 839-850. doi: 10.1071/FP12049

Poorter, H., Niklas, K. J., Reich, P. B., Oleksyn, J., Poot, P., and Mommer, L. (2012b). Biomass allocation to leaves, stems and roots: meta-analyses of interspecific variation and environmental control. New Phytol. 193, 30-50. doi: 10.1111/j. 1469-8137.2011.03952.x

Reinhart, K. O., and Vermeire, L. (2017). Power and limitation of soil properties as predictors of variation in peak plant biomass in a northern mixed-grass prairie. Ecol. Indic. 80, 268-274. doi: 10.1016/j.ecolind.2017. 05.041

Rhazi, M., Grillas, P., Rhazi, L., Charpentier, A., and Médail, F. (2009). Competition in microcosm between a clonal plant species (Bolboschoenus maritimus) and a rare quillwort (Isoetes setacea) from Mediterranean temporary pools of southern France. Hydrobiologia 634, 115-124. doi: 10.1007/s10750-0099887-5

Schmid, B. (1987). Clonal integration and population structure in perennials, effects of severing rhizome connection. Ecology 68, 2016-2022. doi: 10.2307/ 1939892

Villar, R., Veneklaas, E. J., Jordano, P., and Lambers, H. (1998). Relative growth rate and biomass allocation in 20 Aegilops (Poaceae) species. New Phytol. 140, 425-437. doi: 10.1046/j.1469-8137.1998.00286.x

Wang, L., Li, L., Chen, X., Tian, X., Wang, X., and Luo, G. (2014). Biomass allocation patterns across China's terrestrial biomes. PLoS One 9:e93566. doi: 10.1371/journal.pone.0093566

Wang, L., Niu, K., Yang, Y., and Zhou, P. (2010). Patterns of aboveand belowground biomass allocation in China's grasslands: evidence from individual-level observations. Sci. China Life Sci. 53, 851-857. doi: 10.1007/ s11427-010-4027-z

Wang, Z., Li, L., Han, X., and Dong, M. (2004). Do rhizome severing and shoot defoliation affect clonal growth of Leymus chinensis at ramet population level? Acta Oecol. 26, 25-260. doi: 10.1016/j.actao.2004.08.007

Wu, G., Zhang, Z., Wang, D., Shi, Z., and Zhu, Y. (2014). Interactions of soil water content heterogeneity and species diversity patterns in semi-arid steppes on the Loess Plateau of China. J. Hydrol. 519, 1362-1367. doi: 10.1016/j.jhydrol.2014. 09.012

Xiao, C., Zhang, X., Zhao, J., and Wu, G. (2001). Response of seedlings of three dominant shrubs to climate warming in Ordos Plateau. Acta Bot. Sin. 43, 736-741.

Yang, C., and Yang, L. (1998). Plasticity of clonal modules of Leymus chinensis in response to different environments. Chinese J. Appl. Ecol. 9, $265-268$. 
Yang, X., Zhang, W., and He, Q. (2019). Effects of intraspecific competition on growth, architecture and biomass allocation of Quercus Liaotungensis. J. Plant Inter. 14, 284-294. doi: 10.1080/17429145.2019.1629656

Yang, Y., Dou, Y., An, S., and Zhu, Z. (2018). Abiotic and biotic factors modulate plant biomass and root/shoot (R/S) ratios in grassland on the Loess Plateau, China. Sci. Total Environ. 636, 621-631. doi: 10.1016/j.scitotenv.2018.04.260

Yang, Y., Fang, J., Chen, J., and Han, W. (2009). Above- and belowground biomass allocation in Tibetan grasslands. J. Veget. Sci. 20:184. doi: 10.1111/j.1654-1103. 2009.05566.x

Yang, Y., Fang, J., Ma, W., Guo, D., and Mohammat, A. (2010). Large-scale pattern of biomass partitioning across China's grassland. Glob. Ecol. Biogeogr. 19, 268-277. doi: 10.1111/j.1466-8238.2009.00502.x

Yang, Y., and Luo, Y. (2011). Isometric biomass partitioning pattern in forest ecosystems: evidence from temporal observations during stand development. J. Ecol. 99, 431-437. doi: 10.1111/j.1365-2745.2010.01774.x

$\mathrm{Yu}$, M., Lin, W., and Xue, L. (2019). Precipitation-driven changes in biomass allocation pattern for forests in China. Int. J. Agric. Biol. 21, 1049-1054. doi: 10.17957/IJAB/15.0993

Zhang, B., Zhu, J., Pan, Q., Liu, Y., Chen, S., Chen, D., et al. (2017). Grassland species respond differently to altered precipitation amount and pattern. Environ. Exp. Bot. 137, 166-176. doi: 10.1016/j.envexpbot.2017.02.006
Zhang, H., Gao, Y., Tasisa, B. Y., Baskin, J. M., Baskin, C. C., Lu, X., et al. (2019). Divergent responses to water and nitrogen addition of three perennial bunchgrass species from variously degraded typical steppe in Inner Mongolia. Sci. Total Environ. 647, 1344-1350. doi: 10.1016/j.scitotenv.2018.08.025

Zhang, Y., Zhang, Q., and Sammul, M. (2012). Physiological integration ameliorates negative effects of drought stress in the clonal herb Fragaria orientalis. PLoS One 7:e44221. doi: 10.1371/journal.pone.0044221

Zhou, L., Hong, Y., Li, C., Lu, C., He, Y., Shao, J., et al. (2020). Responses of biomass allocation to multi-factor global change: a global synthesis. Age. Ecosyst Environ. 304:107115. doi: 10.1016/j.agee.2020.107115

Conflict of Interest: The authors declare that the research was conducted in the absence of any commercial or financial relationships that could be construed as a potential conflict of interest.

Copyright (c) $2021 \mathrm{Liu}, \mathrm{Xu}, \mathrm{Li}$, Wang, Li and De Boeck. This is an open-access article distributed under the terms of the Creative Commons Attribution License (CC BY). The use, distribution or reproduction in other forums is permitted, provided the original author(s) and the copyright owner(s) are credited and that the original publication in this journal is cited, in accordance with accepted academic practice. No use, distribution or reproduction is permitted which does not comply with these terms. 